\title{
Comparison of Four Growth Curve Models for Fortnightly Body Weights in Japanese Quail
}

\author{
Shubhankar Sharma, Saroj Kumar Sahoo", Shakti Kant Dash and Prem Prakash Dubey \\ Department of Animal Genetics and Breeding, Guru Angad Dev Veterinary and Animal Sciences, University, Ludhiana, INDIA \\ "Corresponding author: SK Sahoo; E-mail: saroj6804@gmail.com
}

Received: 10 Sept., 2021

Revised: 26 Sept., 2021

Accepted: 30 Sept., 2021

\begin{abstract}
The growth curve parameters of Japanese quail (Coturnix coturnix japonica) help in developing breeding strategies by modifying the management practices and can be useful in pre-selection of the birds as it provides prediction of future growth at any age. The study was conducted on fortnightly body weights of 681 black and 565 white plumage Japanese Quails. Four growth curve models viz. Gompertz, Von Bertalanffy, Richard's and Logistic functions were fitted to the body weights for estimation of the curve parameters and identification of the best function based on root mean squares error (RMSE) values. The parameter estimates viz. asymptotic (mature) weight, scaling parameter, maturing rate and shape parameter were ranging from 189.34$217.20,0.92-15.86,0.35-0.68$ and $0.55-0.73$, respectively. The RMSE values were $3.12,4.50,1.77$ and $2.21 \mathrm{~g}$ for overall data; $3.48,4.62,2.14$ and $2.28 \mathrm{~g}$ for male quails; $3.58,5.00,2.48$ and $2.97 \mathrm{~g}$ for female ones; 3.83, 4.88, 3.03 and $3.27 \mathrm{~g}$ for black quails; and 3.08, 4.63, 2.65 and $1.87 \mathrm{~g}$ for white quails; respectively using these functions. Richards function was the best fit for overall, male, female and black categories of observations whereas Logistic function had the better fit for white quails than Richards function.
\end{abstract}

\section{HIGHLIGHTS}

(0 Four growth curve functions were fitted to the fortnightly body weights in black and white strains of Japanese quails.

(0 Richards function had the best fit for different classifications followed by Logistic function based on RMSE values.

Keywords: Asymptotic weight, growth curve, Japanese quail, RMSE

Japanese quails are considered as a model in poultry related research for genetic study because of their short generation interval, high adaptability, rapid growth rate, less capital requirement, better feed efficiency, high disease resistance, fast reproduction, high rate of lay and so on. The growth of birds is a function of both genetics and environment where the change leading to substantial increase in size, shape, weight, etc is accompanied by the utilization of resources. The growth curves are mathematical equations which summarizes the transformation brought about by weight gain in regular intervals. There are two important stages of the growth curve which is sigmoid in shape. The inflection/maximum rate of growth is the first one and asymptote/highest value with further zero/no growth is the second phase.
The parameters of the growth curve are valuable tools for making selection and culling decisions. The critical variations unfolded by random events and environmental means can be studied by the growth parameters (Aggrey, 2003) by modifying the genetic makeup or management practices. Various selection experiments (Narianc et al., 2014; Kaplan et al., 2016) have been conducted on the utility of growth functions and their importance. Accordingly, the study was undertaken to compare the growth curve models and estimate the curve parameters in Japanese quails.

How to cite this article: Sharma, S., Sahoo, S.K., Dash, S.K. and Dubey, P.P. (2021). Comparison of Four Growth Curve Models for Fortnightly Body Weights in Japanese Quail. J. Anim. Res., 11(05): 895-899.

Source of Support: None; Conflict of Interest: None क्ष 


\section{MATERIALS AND METHODS}

The present investigation were carried out on two strains (black and white) of Japanese quails maintained at poultry breeding farm under Directorate of Livestock Farms of Guru Angad Dev Veterinary and Animal Sciences University (GADVASU), Ludhiana. The study was conducted on 565 white (141 male and 424 female) and 681 black (173 male and 508 female) plumage Japanese quails during 2019-20.

Four growth curve models viz. Gompertz, Von Bertalanffy, Richard's and Logistic functions were fitted to the least squares mean (SPSS software 24.0) fortnightly bodyweights (hatch, $2^{\text {nd }}, 4^{\text {th }}, \ldots . .20^{\text {th }}$ week) of Japanese Quails.

1. Gompertz function

$$
Y_{t}=A * e\{-B * e(-K * t)\}
$$

2. Von Bertalanffy function

$$
Y_{t}=A *\{1-B * e(-K * t)\}^{3}
$$

3. Richard's function

$$
Y_{t}=(B * A) /\left\{\left[B^{D}+\left(A^{D}-B^{D}\right) * e(-K * t)\right]^{(1 / D)}\right\}
$$

4. Logistic function

$$
Y_{t}=A /\{1+B * e(-K * t)\}
$$

Where,

$$
\begin{aligned}
& Y_{t}=\text { body weight }(\mathrm{g}) \text { of birds at } \mathrm{t} \text { weeks of age } \\
& A=\text { asymptotic (mature) weight when time goes to } \\
& \text { infinity } \\
& B=\text { scaling parameters (constant of integration) related } \\
& \text { with initial values of weight } \\
& K=\text { maturing rate (instantaneous growth rate) } \\
& D=\text { shape parameter }
\end{aligned}
$$

The most suitable model was identified on the basis of the lowest root mean square error (RMSE) value using Microsoft excel solver.

\section{RESULTS AND DISCUSSION}

The least squares mean fortnightly body weights of different categories of observations (overall, male, female, black and white) of Japanese quails are presented in Table 1. For both male and female quails, black plumage quails had lower body weights than the white plumage through different ages which are in agreement with the findings of Bagh et al. (2016). Body weights at fortnight intervals were used for fitting the growth curve functions. The RMSE values and parameter estimates of different growth curve functions of different classification of observations are presented in Table 2. The fitting of the curves using the four functions (Gompertz, von Bertalanffy, Richards and Logistic) viz. overall, male, female, black and white quails are presented graphically in Figs. 1 to 4.

For Gompertz function the asymptotic (mature) weight (A) ranged from 191.43 to 215.94; scaling parameter (B) from 3.92 to 4.12 ; and maturing rate $(\mathrm{K})$ from 0.40 to 0.46 . However, Raji et al. (2014) reported the values of model parameters of A, B and $\mathrm{K}$ as $132.71 \pm 1.41,0.9338 \pm 0.03$ and $0.3765 \pm 0.01 \mathrm{in}$ male and $168.83 \pm 1.7121,0.9507 \pm 0.02$ and $0.3262 \pm 0.01$ in female quails, respectively. Adedeji et al. (2017) reported these estimates as $155.40 \pm 2.333$, $2.705 \pm 0.281$ and $0.045 \pm 0.003$ in Japanese quails of Nigeria. Our results are supported by findings of Kaplan and Gurcan (2018) for A, B and K that are 222.8, 3.494, 0.059 and 287.7, 3.588, 0.051; respectively in male and female quails. Haqani et al. (2021) also reported these estimates as 185.46, 6.3288, 0.5434 and 226.53, 6.0278, 0.4917 in large sized male and female quails, respectively.

Using von Bertalanffy function, parameter estimates of A, $\mathrm{B}$ and $\mathrm{K}$ ranged from 192.10 to $217.20 ; 0.92$ to 0.97 and 0.35 to 0.41 ; respectively. Adedeji et al. (2017) reported these parameters as $156.60 \pm 2.447,0.656 \pm 0.053$ and $0.039 \pm 0.003$ in 235 numbers of Japanese quails. Kaplan and Gurcan (2018) reported these estimates using this function as 265.6, 0.740, 0.039 in male and 374.8, 0.751, 0.031 in female ones.

The estimates for shape parameter (D) and A, B, K using Richards function ranged from 0.55 to $0.73 ; 189.78$ to 213.99 ; 9.36 to 9.88 and 0.51 to 0.62 ; respectively. Sezer and Tarhan (2005) also reported that these estimates of $\mathrm{A}, \mathrm{B}, \mathrm{K}$ and $\mathrm{D}$ ranged from 182.102 to $261.727,7.437$ to $8.630,0.067$ to 0.113 and 0.170 to 0.618 while comparing among three varieties (white, black and wild) within male 
Table 1: Least squares mean of fortnightly body weights (BW) in Japanese quails

\begin{tabular}{lllllllllll}
\hline \multirow{2}{*}{ BW } & \multicolumn{3}{c}{ Overall } & \multicolumn{3}{c}{ Male } & \multicolumn{3}{c}{ Female } & \multicolumn{2}{c}{ Black } & White \\
\cline { 2 - 11 } & $\mathbf{N}$ & $\boldsymbol{\mu} \pm \mathbf{S E}$ & $\mathbf{N}$ & $\boldsymbol{\mu} \pm \mathbf{S E}$ & $\mathbf{N}$ & $\boldsymbol{\mu} \pm \mathbf{S E}$ & $\mathbf{N}$ & $\boldsymbol{\mu} \pm \mathbf{S E}$ & $\mathbf{N}$ & $\boldsymbol{\mu} \pm \mathbf{S E}$ \\
\hline 0D (Hatch) & 1246 & $7.01 \pm 0.04$ & 314 & $7.01 \pm 0.07$ & 932 & $7.02 \pm 0.04$ & 681 & $6.64 \pm 0.05$ & 565 & $7.39 \pm 0.06$ \\
2W & 1232 & $40.36 \pm 0.30$ & 311 & $39.80 \pm 0.51$ & 921 & $40.92 \pm 0.30$ & 676 & $40.09 \pm 0.38$ & 556 & $40.64 \pm 0.42$ \\
4W & 1221 & $91.91 \pm 0.74$ & 310 & $92.37 \pm 1.24$ & 911 & $91.45 \pm 0.75$ & 670 & $89.25 \pm 0.92$ & 551 & $94.56 \pm 1.01$ \\
6W & 1217 & $150.77 \pm 0.90$ & 310 & $149.52 \pm 1.52$ & 907 & $152.01 \pm 0.92$ & 668 & $145.73 \pm 1.14$ & 549 & $155.80 \pm 1.24$ \\
8W & 1204 & $183.14 \pm 0.86$ & 307 & $176.92 \pm 1.45$ & 897 & $189.36 \pm 0.87$ & 664 & $177.15 \pm 1.07$ & 540 & $189.14 \pm 1.18$ \\
10W & 812 & $194.34 \pm 0.99$ & 210 & $185.21 \pm 1.64$ & 602 & $203.46 \pm 1.01$ & 423 & $185.52 \pm 1.26$ & 389 & $203.15 \pm 1.31$ \\
12W & 809 & $198.95 \pm 0.96$ & 209 & $188.88 \pm 1.60$ & 600 & $209.02 \pm 0.98$ & 422 & $188.68 \pm 1.23$ & 387 & $209.22 \pm 1.28$ \\
14W & 807 & $198.40 \pm 0.91$ & 208 & $186.42 \pm 1.51$ & 599 & $210.38 \pm 0.93$ & 420 & $186.77 \pm 1.16$ & 387 & $210.04 \pm 1.21$ \\
16W & 807 & $201.72 \pm 0.98$ & 208 & $186.89 \pm 1.62$ & 599 & $216.54 \pm 0.99$ & 420 & $192.67 \pm 1.24$ & 387 & $210.76 \pm 1.29$ \\
18W & 801 & $204.22 \pm 1.04$ & 204 & $191.12 \pm 1.74$ & 597 & $217.31 \pm 1.05$ & 417 & $198.76 \pm 1.32$ & 384 & $209.67 \pm 1.39$ \\
20W & 780 & $201.79 \pm 1.05$ & 187 & $193.38 \pm 1.82$ & 593 & $210.21 \pm 1.00$ & 401 & $193.66 \pm 1.36$ & 379 & $209.92 \pm 1.33$ \\
\hline
\end{tabular}

Table 2: Estimates of growth curve parameters for the studied growth functions in Japanese quails

\begin{tabular}{|c|c|c|c|c|c|}
\hline Functions & $\mathbf{A}$ & B & $\mathbf{K}$ & D & RMSE (g) \\
\hline \multicolumn{6}{|l|}{ Gompertz } \\
\hline Overall & 203.60 & 4.01 & 0.43 & & 3.12 \\
\hline Male & 191.43 & 4.12 & 0.46 & & 3.48 \\
\hline Female & 215.94 & 3.96 & 0.40 & & 3.58 \\
\hline Black & 194.67 & 3.92 & 0.43 & & 3.83 \\
\hline White & 212.52 & 4.10 & 0.43 & & 3.08 \\
\hline \multicolumn{6}{|c|}{ Von Bertalanffy } \\
\hline Overall & 204.55 & 0.94 & 0.37 & & 4.50 \\
\hline Male & 192.10 & 0.97 & 0.41 & & 4.62 \\
\hline Female & 217.20 & 0.92 & 0.35 & & 5.00 \\
\hline Black & 195.64 & 0.92 & 0.37 & & 4.88 \\
\hline White & 213.47 & 0.96 & 0.37 & & 4.63 \\
\hline \multicolumn{6}{|l|}{ Richard's } \\
\hline Overall & 201.84 & 9.58 & 0.55 & 0.60 & 1.77 \\
\hline Male & 189.78 & 9.54 & 0.62 & 0.73 & 2.14 \\
\hline Female & 213.99 & 9.88 & 0.51 & 0.55 & 2.48 \\
\hline Black & 192.96 & 9.36 & 0.55 & 0.60 & 3.03 \\
\hline White & 210.71 & 9.82 & 0.55 & 0.62 & 2.65 \\
\hline \multicolumn{6}{|l|}{ Logistic } \\
\hline Overall & 201.02 & 15.30 & 0.64 & & 2.21 \\
\hline Male & 189.34 & 15.86 & 0.68 & & 2.28 \\
\hline Female & 212.88 & 15.09 & 0.60 & & 2.97 \\
\hline Black & 192.15 & 15.01 & 0.64 & & 3.27 \\
\hline White & 209.89 & 15.59 & 0.63 & & 1.87 \\
\hline
\end{tabular}




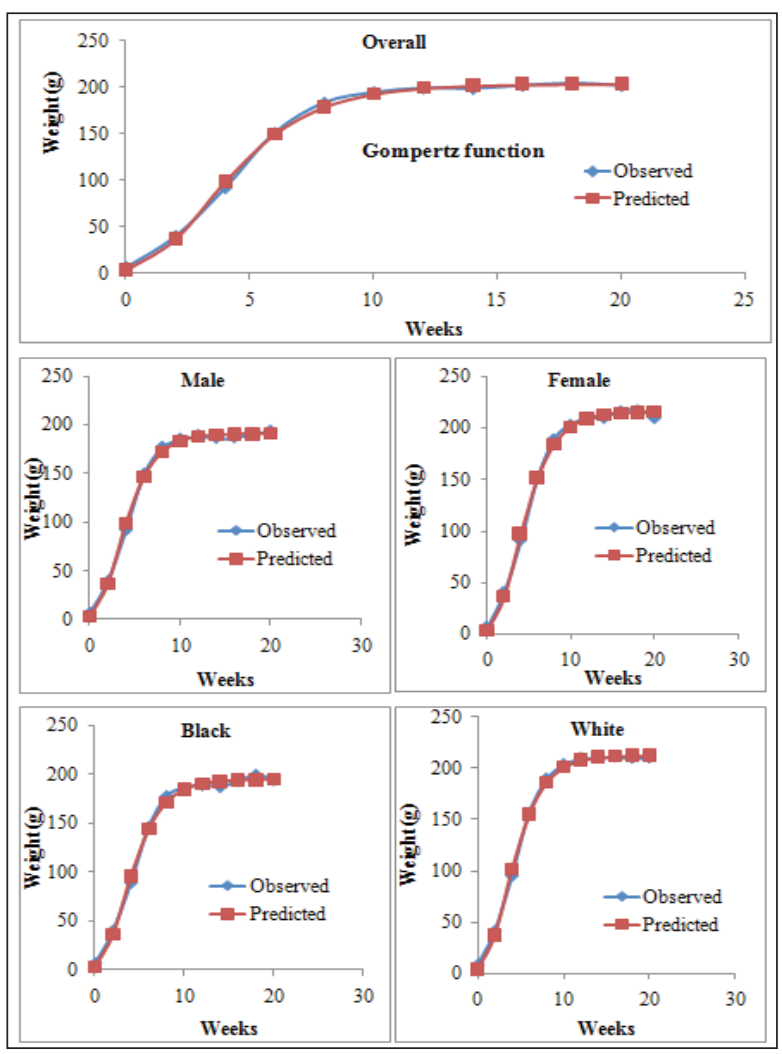

Fig. 1: Observed and predicted fortnightly body weights by Gompertz Function

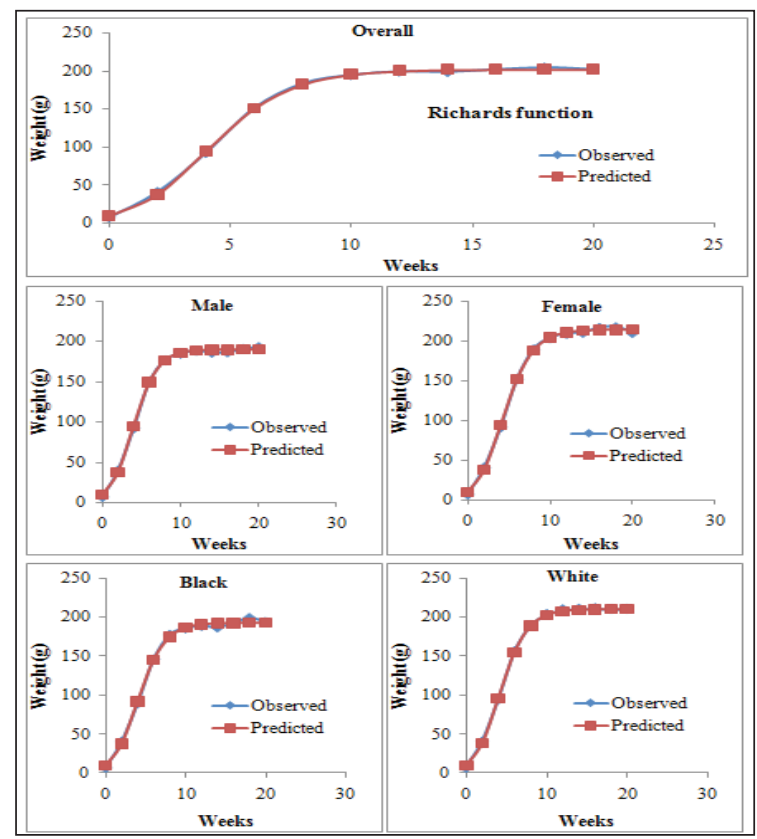

Fig. 3: Observed and predicted fortnightly body weights by Richard's Function

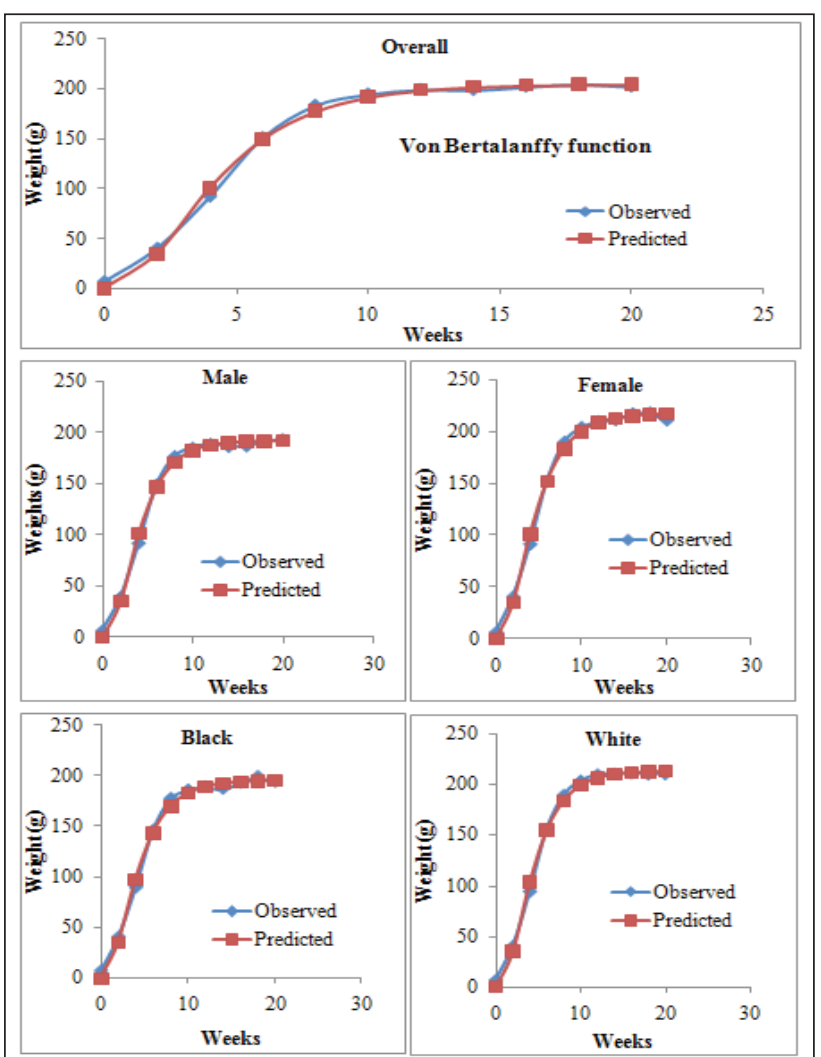

Fig. 2: Observed and predicted fortnightly body weights by Von Bertalanffy Function

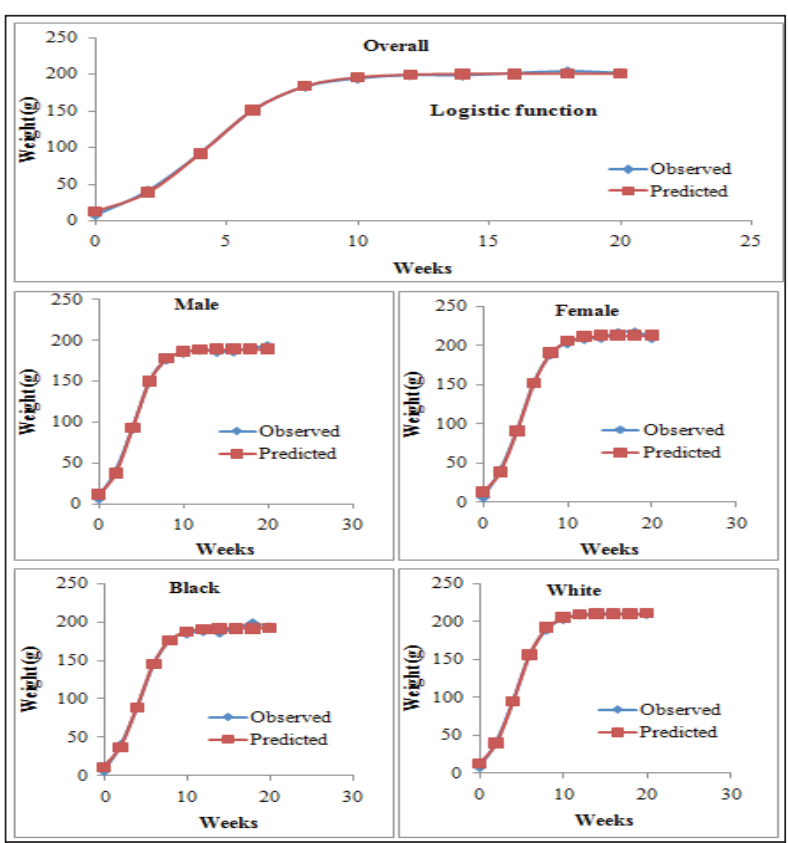

Fig. 4: Observed and predicted fortnightly body weights by Logistic Function 
and female Japanese quails. Our findings are in agreement with the observation of Haqani et al. (2021) who reported these estimates as $0.4327,221.20,3.3941,0.6037$ and $0.3592,183.98,2.1132,0.6437$ in large sized female and male quails, respectively.

The range of A, B and $\mathrm{K}$ parameters using Logistic function were 189.34 to $212.88 ; 15.01$ to 15.86 and 0.60 to 0.68 , respectively. The values are $153.40 \pm 2.368,7.543 \pm 1.506$ and $0.065 \pm 0.006$ as per reports of Adedeji et al. (2017) in Japanese quails of Nigeria. Our findings are in agreement with that of Kaplan and Gurcan (2018) who reported these estimates as 183.3, 15.492, 0.118 and 219.4, 16.679, 0.109 in male and female Japanese quails, respectively.

The root mean squares (RMSE) values for Gompertz, von Bertalanffy, Richards and Logistic functions ranged from 3.08 to $3.83 \mathrm{~g}, 4.62$ to $5.00 \mathrm{~g}, 1.77$ to $3.03 \mathrm{~g}$ and 1.87 to $3.27 \mathrm{~g}$, respectively. Adedeji et al. (2017) reported Mean Square Error (MSE) values as 65.744, 51.363 and 49.731 using Logistic, Gompertz and von Bertalanffy functions, respectively. Our results are supported by Kaplan and Gurcan (2018) who reported the MSE values using Gompertz, von Bertalanffy, Richards and Logistic functions as 4.00, 4.90, 3.62, 17.68 and 6.10, 8.86, 6.01, 13.17 in female and male Japanese quails, respectively. Reports of Beiki et al. (2013) also confirms better fit of Richard's function by MSE criteria and the values were $18.987,11.502,9.514$ and 21.894 ; respectively for unselected random bred Japanese quails. Experiments of Haqani et al. (2021) also in agreement with our findings who reported the RMSE values for Gompertz, Richards and Logistic models as 2.140, 1.996, 3.433 and 2.995, $2.699,4.056$ for large sized male and females, respectively whereas the corresponding values were 1.983, 1.965, 3.065 and $1.386,1.361,2.746$ for normal sized male and females, respectively.

\section{CONCLUSION}

The lowest RMSE value was observed in Richard's model for overall, male, female and black categories of quails, whereas logistic function had lowest RMSE for the white Japanese Quails. Richard's function was found out to be the best fit followed by logistic function for the body weight gain through different fortnightly weeks in Japanese quails. It is recommended to take into account the parameter estimates of these functions in selection and breeding programmes.

\section{ACKNOWLEDGEMENTS}

The authors are thankful to the Director, Livestock Farms, GADVASU, Ludhiana for providing necessary facilities for this research work.

\section{REFERENCES}

Adedeji, O.A., Omolara, A.M., Osamede, O.H. and Emmanuel, S.A. 2017. Analysis of growth models of Japanese quails (Coturnix coturnix japonica) in Nigeria. Thai J. Agri. Sci., 50(3-4): 155-165.

Aggrey, S.E. 2003. Dynamics of relative growth rate in Japanese quail lines divergently selected for growth and their control. Growth Dev. Aging., 67: 47-54.

Bagh, J., Panigrahi, B., Panda, N., Pradhan, C.R., Mallik, B.K., Majhi, B. and Rout, S.S. 2016. Body weight, egg production, and egg quality traits of gray, brown, and white varieties of Japanese quail (Coturnix coturnix japonica) in coastal climatic condition of Odisha. Vet. World, 9(8): 832-836.

Beiki, H., Pakdel, A., Moradi-shahrbabak, M. and Mehrban, H. 2013. Evaluation of growth functions on Japanese quail lines. J. Poultry Sci., 50: 20-27.

Haqani, M.I., Kawamura, K., Takenouchi, A., Kabir, M.H., Nakamura, Y., Ishikawa, A. and Tsudzuki, M. 2021. A growth performance and nonlinear growth curve functions of largeand normal-sized Japanese quail (Coturnix japonica). $J$. Poultry Sci., 58(2): 88-96.

Kaplan, S. and Gurcan, E.K. 2018. Comparison of growth curves using nonlinear regression function in Japanese quail. J. App. Anim. Res., 46: 112-117.

Kaplan, S., Narinc, D. and Gurcan, E.K. 2016. Genetic parameter estimates of weekly body weight and Richard's growth curve in Japanese quail. Europian Poultry Sci., 80.

Narinc, D., Karaman, E., Aksoy, T. and Firat, Z.M. 2014. Genetic parameter estimates of growth curve and reproduction traits in Japanese quail. Poultry Sci., 93: 24-30.

Raji, A.O., Mbap, S.T. and Aliyu, J. 2014. Comparison of different models to describe growth of the Japanese quail (Coturnix japonica). Trakia J. Sci., 2:182-188.

Sezer, M. and Tarhan, S. 2005. Model parameters of growth curves of three meat-type lines of Japanese quail. Czech J. Anim. Sci., 50(1): 22-30. 
